\title{
Significance of Immunoglobulin E in Umbilical Blood in Relation to an Allergic Family History, Seasonality, Child Immunity and the Impact of Applied Non-pathogenic E. coli on Children's Microbiome
}

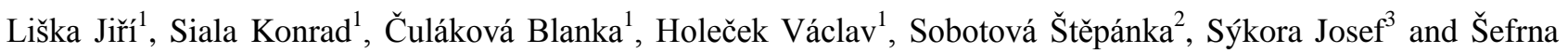 \\ František $^{4}$ \\ 1. Newborn Department, Mulac Hospital, Pilsen 301 00, Czech Republic
}

2. Department of Clinical Chemistry and Hematology, Mulac Hospital, Pilsen 30100 Czech Republic

3. Department of Pediatrics, Faculty of Medicine, Faculty Hospital, Charles University, Pilsen 301 00, Czech Republic

4. Department of Health Accounting and Statistics, University Hospital Pilsen 301 00, Czech Republic

\begin{abstract}
We examined IgE levels in 4,312 samples of umbilical blood taken from children born into families with a positive history of allergy in one or both parents from 1998-2015. At the age of ten days, those with high IgE were given Colinfant Newborn (a lyophilized non-pathogenic strain of $E$. coli) for one month, three times weekly. At 15 months and three years we investigated the levels of IgE, IgA and IgG, and the incidence of illness and allergy. The results revealed that allergy and high umbilical IgE is strongly linked with family history ( $p \leq 0.001$ ). We also detected differences in seasonality, especially with regards to pollen allergies. About $80 \%$ of children treated with Colinfant had significantly reduced IgE and morbidity at 13-15 months and 3 years, and furthermore without any clinical signs of allergy. Surprisingly $20 \%$ of treated children did not have reduced IgE, and yet they did not have any clinical signs of allergy. Normalization of IgA and IgG was seen in $90 \%$ of treated subjects $(p \leq 0.001)$. These levels significantly are correlated with an almost negligible morbidity up to 4 years of life. Our study strongly suggests a positive effect of physiological $E$. coli on the microbiome of children as evidenced by a significantly reduced incidence of allergy and morbidity when applied early in life.
\end{abstract}

Key words: Microbiome, allergy, immunology, newborn, probiotics.

\section{Introduction}

Allergic diseases represent an increasingly important health problem worldwide in recent years. This is evident in all age groups. The roots of this increase are not entirely obvious, though both genetic and environmental factors have been implicated. The occurrence of allergic illnesses in the Czech Republic also continues to rise exponentially, and thus the use of preventive and prognostic methods, particularly in children with an inherently higher risk of allergy, is gaining increased importance.

Corresponding author: Jiří Liška, MD, doctor, C.Sc., research fields: the neonatal department and specialist surgery.
Since the advent of probiotics the effect of probiosis on immunity through alterations of composition and function of the human gut microbiome has been increasingly studied. The exact mechanisms have not yet been clearly defined. The Academy of Sciences of the Czech Republic has suggested that the expression of Th1 and Th2 cytokines in umbilical blood is associated with an increased risk of allergies. The counter-balance of Th1 and Th2 affects IgE production and maturation of the gastrointestinal tract epithelium. A higher expression of interleukin 10 (IL-10) was discovered in the umbilical blood cells of children with allergic mothers. 
This infers a predominant Th2 cell response which encourages the future development of allergy. Reduced expression of the cytokine TGF-Beta among children of allergic mothers may contribute to slower maturing of intestinal epithelium in newborns and therefore lead to increased intestinal permeability of potential allergens. It is known that EGF (epidermal growth factor) in children of non-atopic mothers is higher than those with a history of allergy. It has thus been suggested that an agent that may improve the maturation of the intestinal epithelium may be a possible point of therapy for an atopic child's future immunomodulation.

\section{Materials and Methods}

This study was carried out at a 20-bed unit of the Neonatology Department in a tertiary hospital in Pilsen, in Czech Republic.

From 1998-2003 study subjects were enrolled based upon a positive family (paternal and/or maternal) history of allergy. IgE was measured at birth from umbilical cord blood. Umbilical blood of $2 \mathrm{~mL}$ was centrifuged and analyzed using DPC IMMULITE chemiluminescence analyzer with reference potentials of $1.0 \mathrm{IU} / \mathrm{mL}$ to $2,000 \mathrm{IU} / \mathrm{mL}$. All readings were carried out within 24 hours. Even though hemolyzed samples were analyzed, these samples were not included in the study results. The manufacturers' physiological reference values were given as a maximum of $4 \mathrm{IU} / \mathrm{mL}$.

From 2003-2005 IgE was measured at birth from umbilical cord blood. Umbilical blood of $2 \mathrm{~mL}$ was collected without the use of anticoagulant agents, and analyzed using Radim ELISA kits, calibration range 0.4-1,000 IU, with expected values under 5 years as less than $75 \mathrm{IU} / \mathrm{mL} / 0-75 / \mathrm{IU} / \mathrm{L}$. Children with $\operatorname{IgE}$ values over $0.9 \mathrm{IU} / \mathrm{mL}$ were then included into the test group whereupon Colinfant was given from the age of 7-10 days of life as per manufacturer's instructions. The content of each bottle was dissolved in $1 \mathrm{~mL}$ of liquid (water, tea), and given to the child to drink by the parents. One bottle was administered three times a week for a period of 4 weeks. A control group of umbilical IgE samples taken from 40 subjects was also taken for comparison.

From 2005-2015 IgE was measured at birth from umbilical cord blood. Umbilical blood of $2 \mathrm{~mL}$ was collected without the use of anticoagulant agents, and analyzed using Radim ELISA kits, calibration range 0.4-1,000 IU, with expected values under 5 years as less than $75 \mathrm{IU} / \mathrm{mL} / 0-75 / \mathrm{IU} / \mathrm{L}$. Children with IgE values over $0.9 \mathrm{IU} / \mathrm{mL}$ were then included into the test group whereupon Colinfant was given from the age of 7-10 days of life as per manufacturer's instructions. One bottle was administered three times a week for a period of 4 weeks. These test subjects were seen again 13-15 months and after three years of life whereupon we further established IgE, IgA and IgG values. Determination of IgA was performed using immunoturbidimetric kits IgA K Assay Beckmann coulter on the 480 Beckman Coulter Analyzer. The calibration range was $0.2-8 \mathrm{~g} / \mathrm{L}$, with normal values up to the age of 5 years being $0.30-1.60 \mathrm{~g} / \mathrm{L}$, with expected values for children up to one month of age being 0.3-1.6 g/L. Determination of IgG was also performed using immunoturbidimetric kits IgG Beckham Coulter, on the AU 480 Beckman Coulter Analyzer. The calibration range was $0.004-30 \mathrm{~g}$, with expected values up to 1 year of age being 5.5-14.7 g/L, and up to the age of 15 years of age being 5.5-14.0 g/L. During both encounters all family members of each test subject were invited and questioned regarding the incidence of both general illness as well as allergic symptoms.

It is important to note that umbilical IgA was measured throughout the entire study at birth. This was in order to eliminate the possibility of mixed maternal blood. IgE values throughout the entire study duration were compared with each month of the year to ascertain if there was a correlation with seasonality.

The control group comprised of subjects without a family history of allergy and with normal umbilical 
IgE levels. Subjects with a family history, maternal or paternal, of autoimmune disease, hormonal or on cytostatic therapy were excluded from the study. The control group is used for comparing data at year one, from reference values for this age, and year three which comprised healthy children being followed for secondary enuresis by a nephrologist. Children with endocrine, autoimmune or other organic causes of enuresis were excluded from the data comparison.

\section{Biological Material}

Colinfant Newborn-New Peroral Vaccine-A Probiotic

This is a live per oral vaccine containing lyophilized non-pathogenic E. coli. This strain is able to displace colonization of intestinal tract by pathogenic strains. It is originally patented by the Institute of Serums and Vaccines. Our source of 12 vial batches was derived from the present manufacturer, Dyntec in Terezín. Each vial contains Escherichia coli serotype 083:K24:H31 (minimum 0.8 $\times 10 \mathrm{CFU}$ ), and is representative of a group of bacteria that are part of normal intestinal microflora. The vaccine was registered at the State Institute for Drug Control in 1997 under registration number 59/762/97-C. Use of the strain and preparation of the vaccine was patented in 1989 under number 2645722. $E$. coli, from which the live vaccine is prepared, is a nonpathogenic strain with the above mentioned serotype. It is saved in the collection of type strains under number AO34/86. The strain is highly selected, sensitive to common antibiotics, does not form enterotoxins and does not have a plasmid. Its tremendous colonizing ability is ensured also by the presence of fimbriae demonstrated by hemagglutination. After per oral administration of the suspension, translocation of microbes has been demonstrated only into mesenteric lymph nodes, though not into the spleen, liver and lungs. The strain has excellent colonizing characteristics, occupies receptors in the intestinal mucosa, prevents adherence of pathogens and expels present enteropathogenic strains. In tests, the strain for germ-free piglets was found to be entirely non-pathogenic.

The induction of IgA secretion is particularly significant in newborns, since it partly replaces a deficit of this immunoglobulin. After colonization of newborn GIT, bacterial pathogens disappear from stool, throat and nose. The vaccine strain has been shown to persist in the intestinal tract of colonized newborns for 16 weeks, though it was demonstrated even after several years. The presence of this strain stimulates the formation of specific and non-specific antibodies, demonstrable in the intestinal tract, saliva and serum. This package is designed for 1 patient at the age until 1 year, regardless of the child's weight. The content of the bottle is dissolved in $1 \mathrm{~mL}$ of liquid (water, tea), and given to the child to drink.

One bottle is administered three times a week for a period of 4 weeks. The administration is interrupted during application of antibiotics. It is not recommended to administer the vaccine during the acute stage of diarrheal disease. Colinfant is not available as on over the counter preparation and must be prescribed by a licensed physician.

\section{Statistical Methods}

During Mann Whitney's two sampled selection test, an older named Wilcoxon unpaired test was used, the title adopted from English original. Nowadays Mann-Whitney's American test Wilcoxon unpaired test, Rank correlation-Spearman and Kendall are demanded. Eventually it is possible to tell that Rank Correlation Test was applied because the hypothesis about normality was rejected by using tests of skewness and kurtosis.

\section{Results}

Fig. 1 is a representative graph demonstrating the association between IgE, from umbilical cord blood from newborns born into families with a history of allergy, during individual months of the year 
108 Significance of Immunoglobulin E in Umbilical Blood in Relation to an Allergic Family History, Seasonality, Child Immunity and the Impact of Applied Non-pathogenic E. coli on Children's Microbiome

(2009-2010), and shows that the highest values were during spring and summer.

Fig. 2 demonstrates the values of IgE in serum at the age of 15 months in children with previously high IgE that were treated with Colinfant from 2005-2007. From 116 children that were treated, 106 had significantly reduced IgE. Ten children, however, had no clinical symptoms of allergy and yet maintained significantly high IgE values in their serum.

Fig. 3 demonstrates the values of IgE in serum at the age of 15 months in children with previously high IgE that were treated with Colinfant from 2008-2009. From 98 children that were treated, 86 had significantly reduced IgE. Twelve children, however, had no clinical symptoms of allergy and yet maintained significantly high IgE values in their serum.

Fig. 4 demonstrates the IgE values of Colinfant treated children at the age of 15 months from 2010-2014. From 31 subjects, 25 had very low values, 6 had high values despite not showing any clinical symptoms. For this reason we have included standard deviations.
Fig. 5 demonstrates the values of IgE in serum at the age of 15 months in children with previously high IgE that were treated with Colinfant from 2012-2015. From 90 children that were treated, 75 had significantly reduced IgE. Fifteen children, however, had no clinical symptoms of allergy and yet maintained significantly high IgE values in their serum. Standard deviations are included.

Fig. 6 demonstrates the values of IgE in serum at the age of 3 years in children with previously high IgE that were treated with Colinfant from 2012-2015. From 36 children that were treated, 25 had significantly reduced IgE. Eleven children, however, had no clinical symptoms of allergy and yet maintained significantly high IgE values in their serum. Standard deviations are included.

Fig. 7 demonstrates the average values of IgE in serum at the age of 1 and 3 years in children with previously high IgE that were treated with Colinfant from 2012-2015. Standard deviations are included. Though an increased value of IgE was determined at three years, these children were without any clinical signs of allergy.

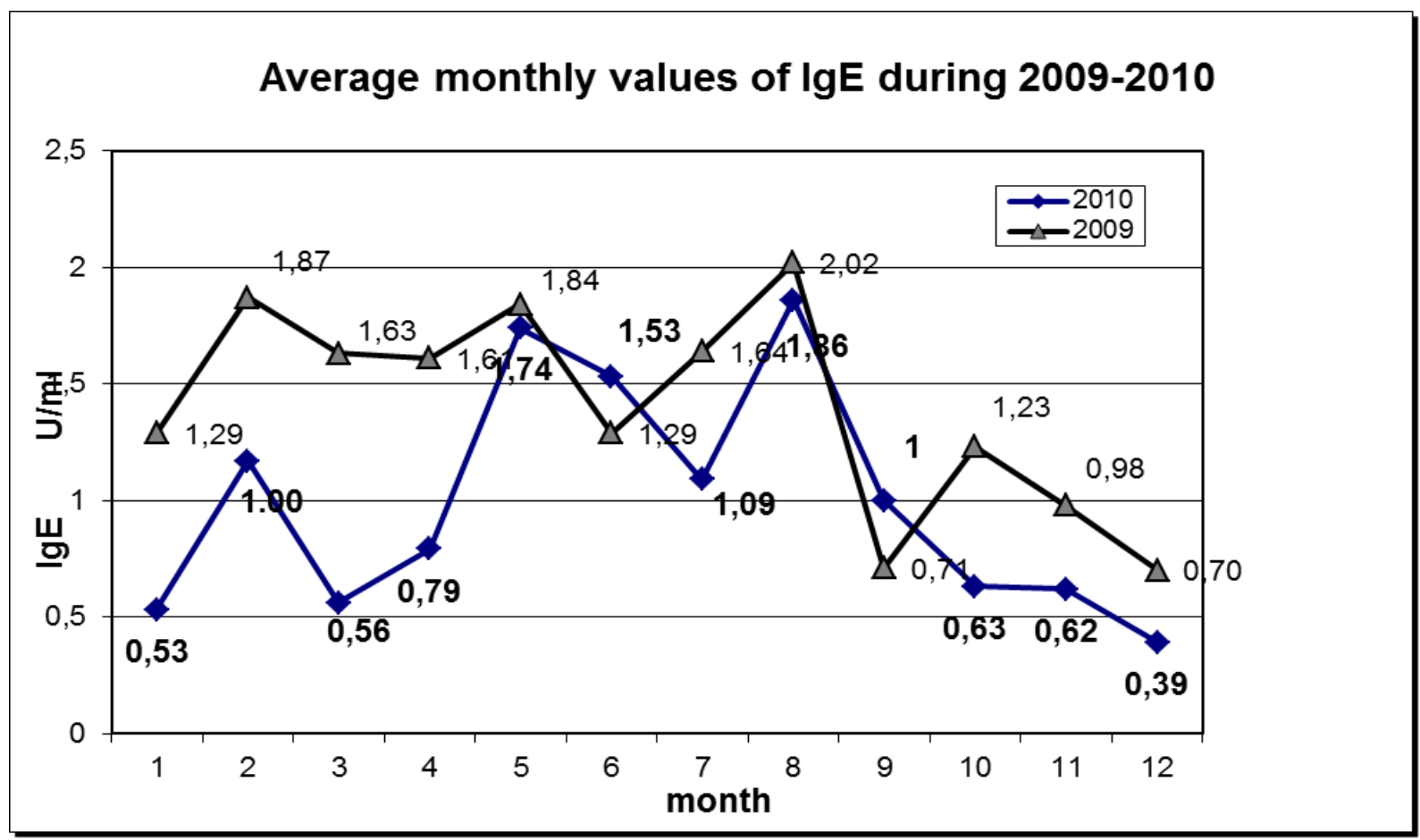

Fig. 1 Average monthly values of IgE during 2009-2010. 
Significance of Immunoglobulin E in Umbilical Blood in Relation to an Allergic Family History, Seasonality, Child Immunity and the Impact of Applied Non-pathogenic E. coli on Children's Microbiome

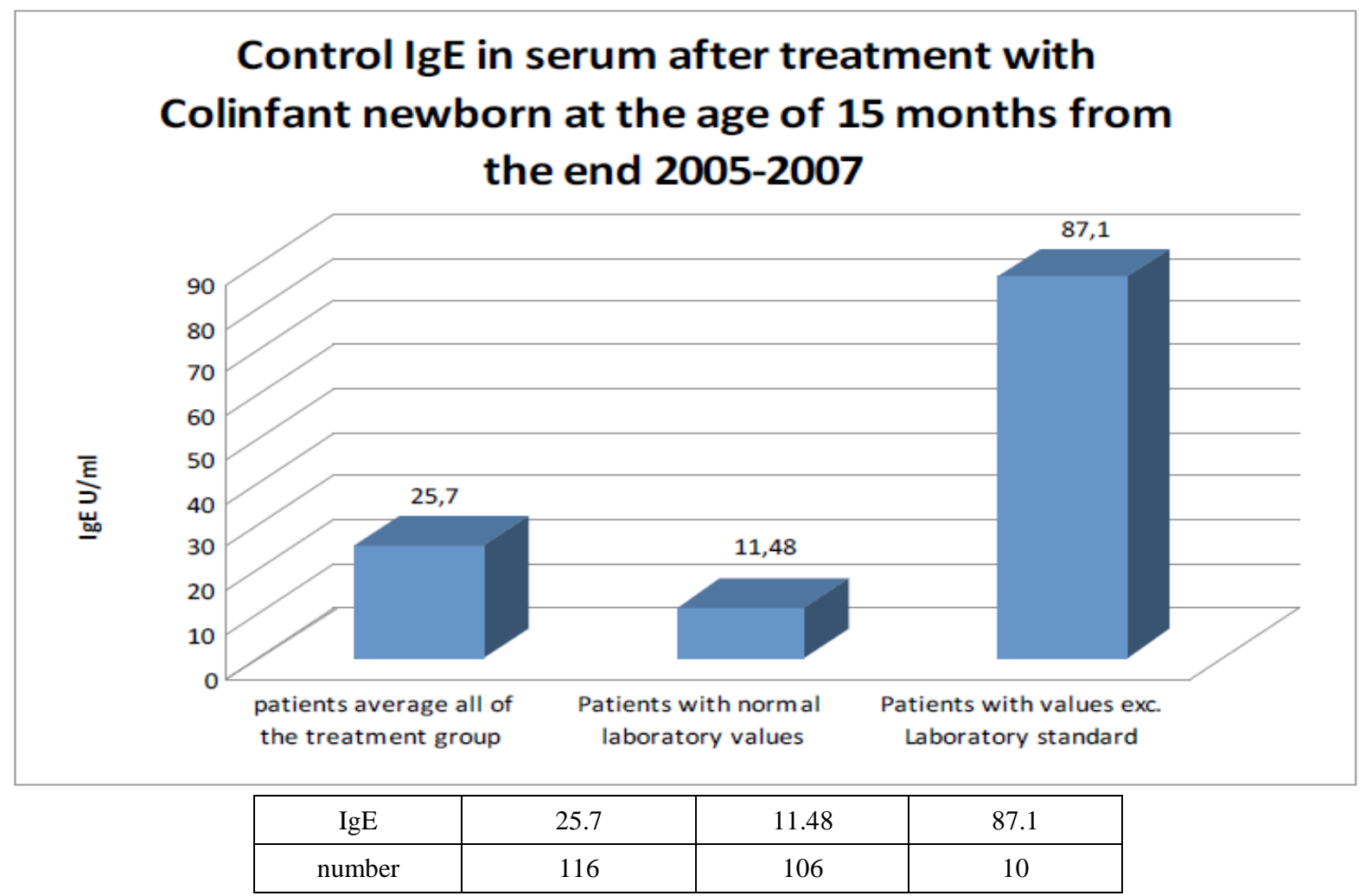

Fig. 2 Control IgE in serum after treatment with Colinfant newborn at the age of 15 months from the end 2005-2007.

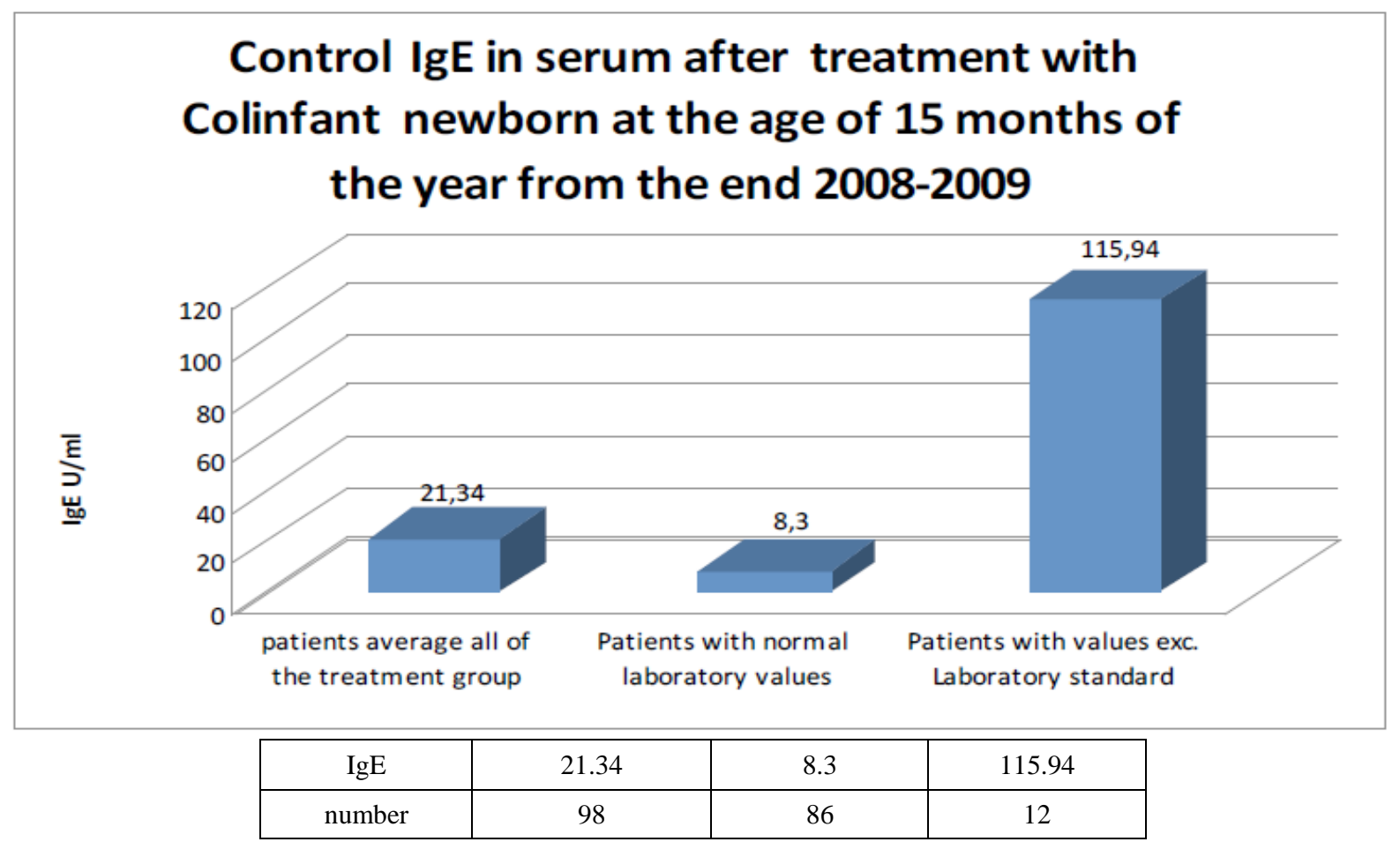

Fig. 3 Control IgE in serum after treatment with Colinfant newborn at the age of 15 months of the year from the end 2008-2009. 
110 Significance of Immunoglobulin E in Umbilical Blood in Relation to an Allergic Family History, Seasonality, Child Immunity and the Impact of Applied Non-pathogenic E. coli on Children's Microbiome

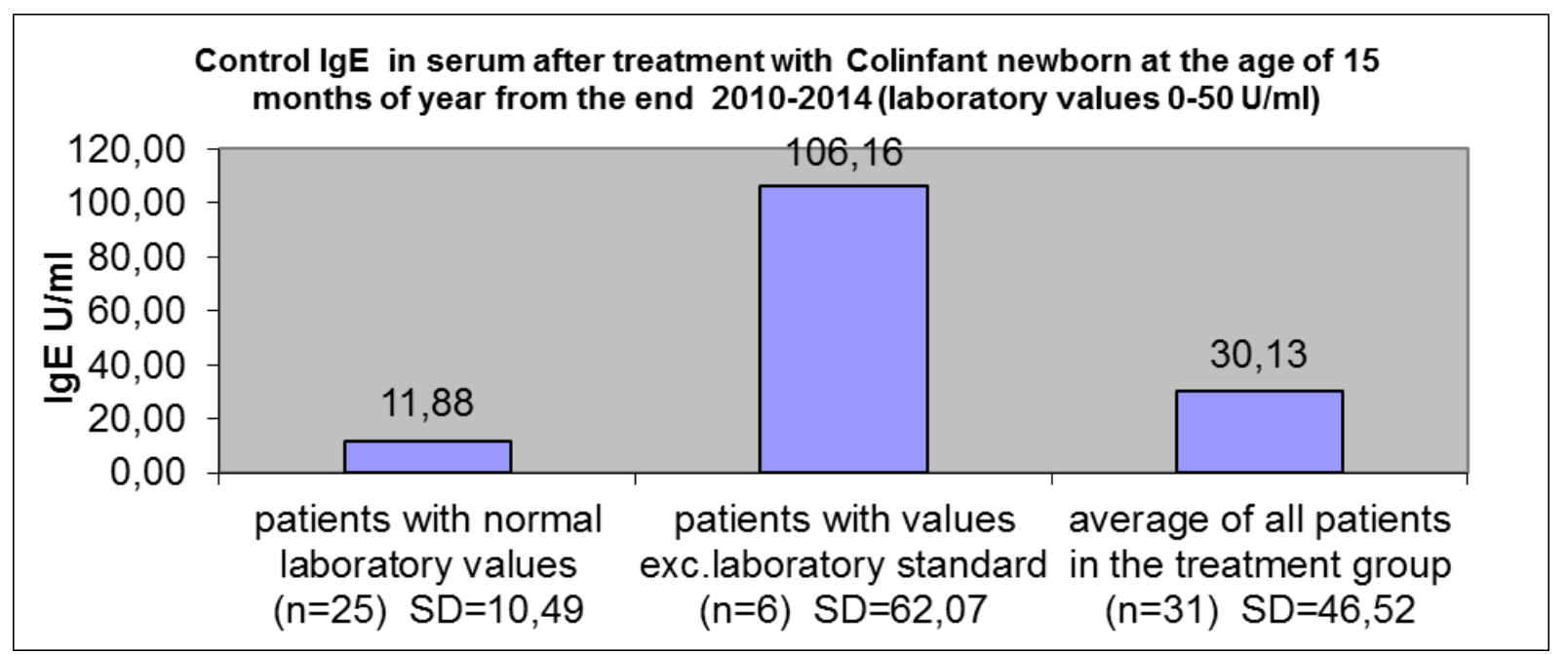

Fig. 4 Control IgE in serum after treatment with Colinfant newborn at the age of 15 months of year from the end 2010-2014.

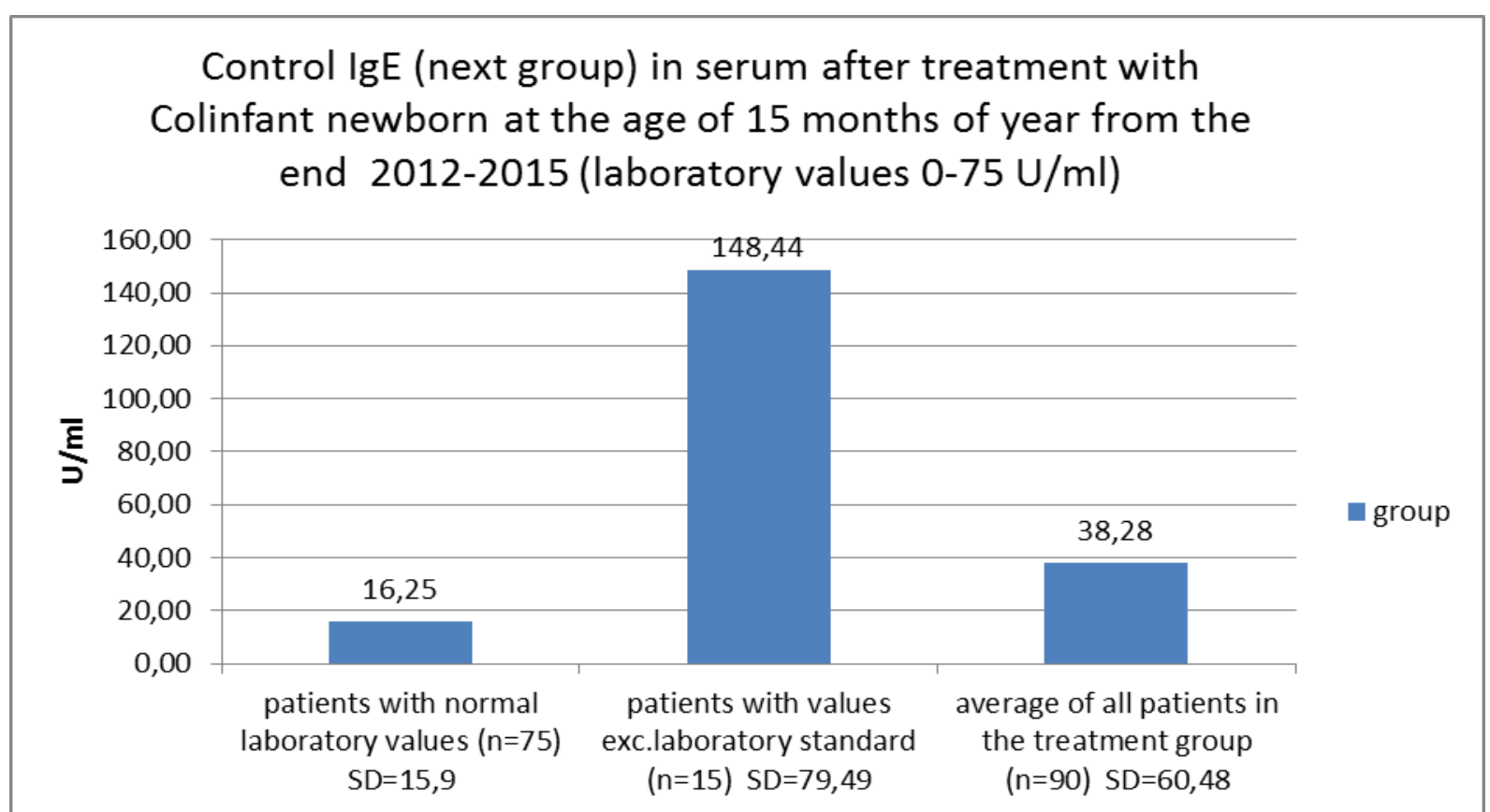

Fig. 5 Control IgE (next group) in serum after treatment with Colinfant newborn at the age of 15 months of year from the end 2012-2015 (laboratory values 0-75 U/ml). 
Significance of Immunoglobulin E in Umbilical Blood in Relation to an Allergic Family History, Seasonality, Child Immunity and the Impact of Applied Non-pathogenic E. coli on Children's Microbiome

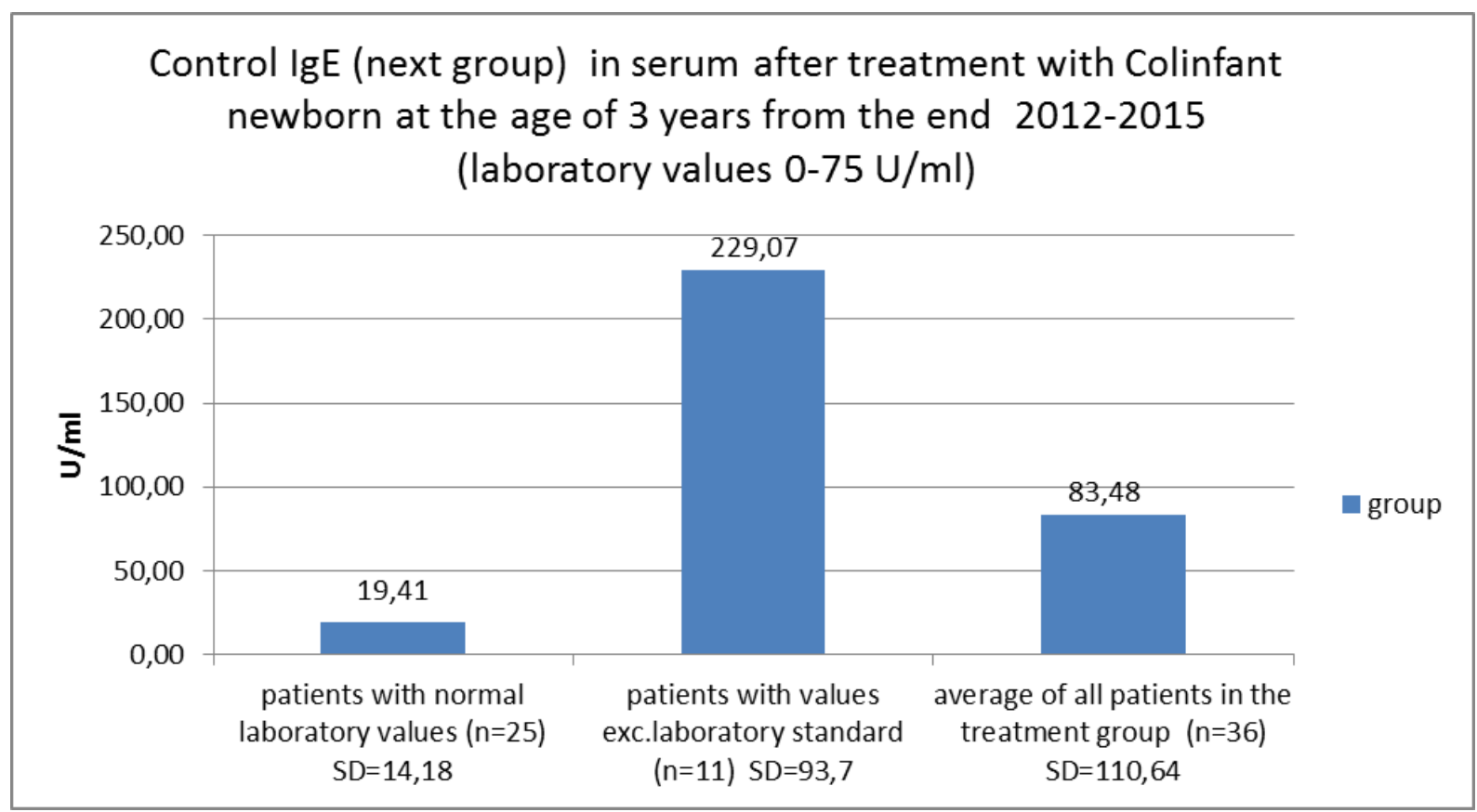

Fig. 6 Control igE (next group) in serium after treatment with Colinfant newborn at the age of 3 years from 2012-2015.

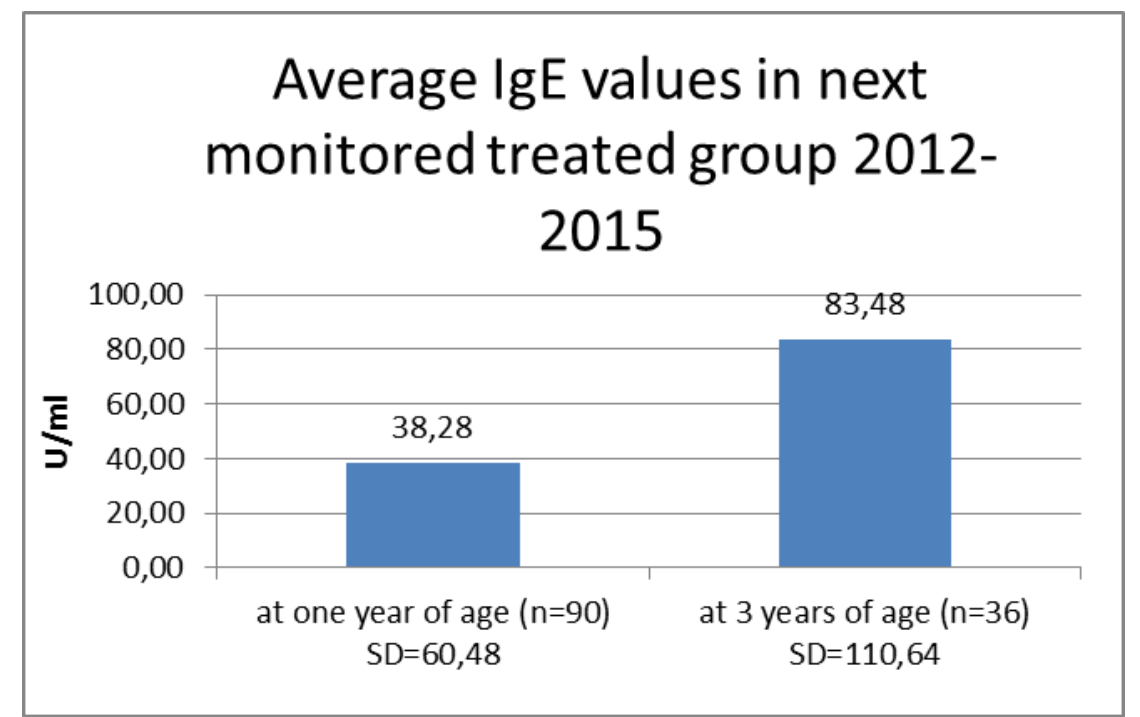

Fig. 7 Average IgE values in next monitored treated group 2012-2015.

Fig. 8 demonstrates average IgG values in the Colinfant treated group at one year of age in individual years as compared with the control group. All treated group values were significantly elevated above controls.

Fig. 9 demonstrates increasing average IgG values in the Colinfant treated group at one year and three years of age during 2010-2014.

Fig. 10 demonstrates increasing average IgG values in the Colinfant treated group from one year to three years of age during 2012-2015.

Fig. 11 demonstrates average IgA values in treated children at the age of 1 and 3 years.

Fig. 12 demonstrates average IgA values in treated children at the age of 3 years.

Fig. 13 demonstrates the percentage of 186 children with a history of illnesses by the age of three years.

Fig. 14 demonstrates the illness rates of siblings of 
112 Significance of Immunoglobulin E in Umbilical Blood in Relation to an Allergic Family History, Seasonality, Child Immunity and the Impact of Applied Non-pathogenic E. coli on Children's Microbiome

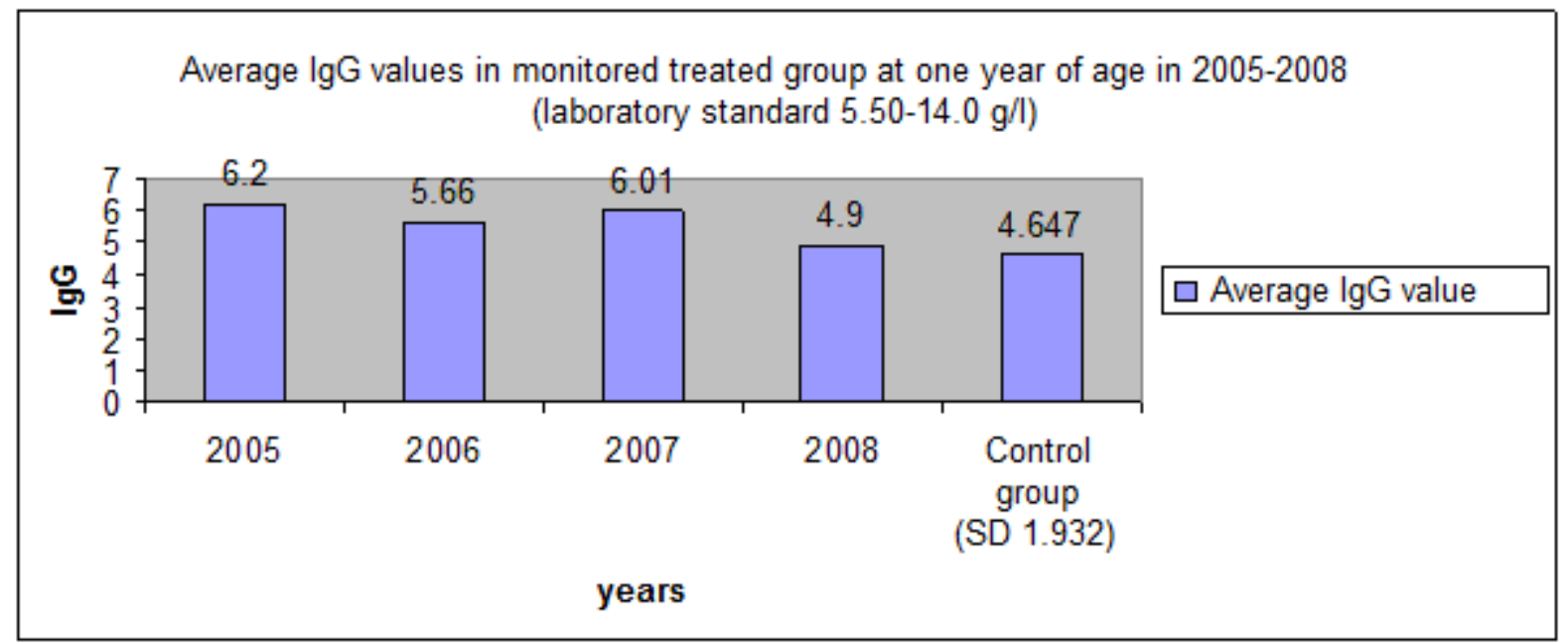

Fig. 8 Average IgG values in monitored group at one year of age in 2005-2008.

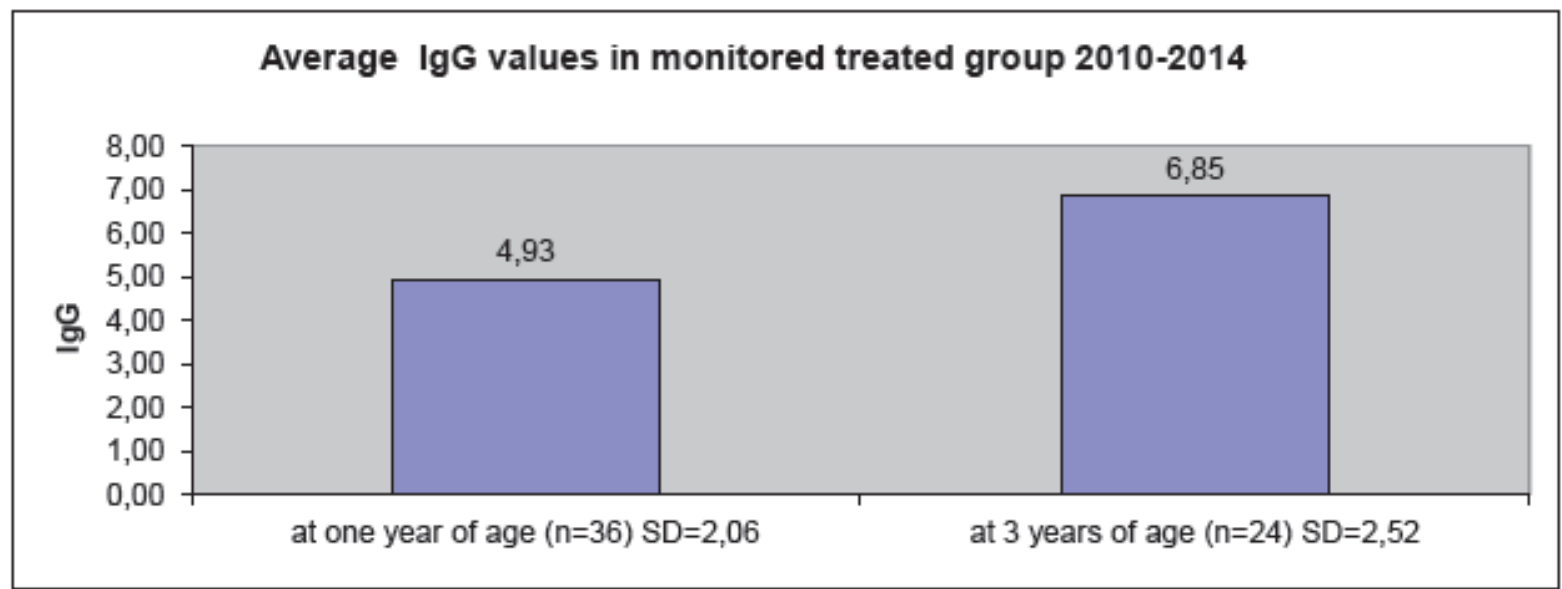

Fig. 9 Average IgE values in monitored treated group 2010-2014.

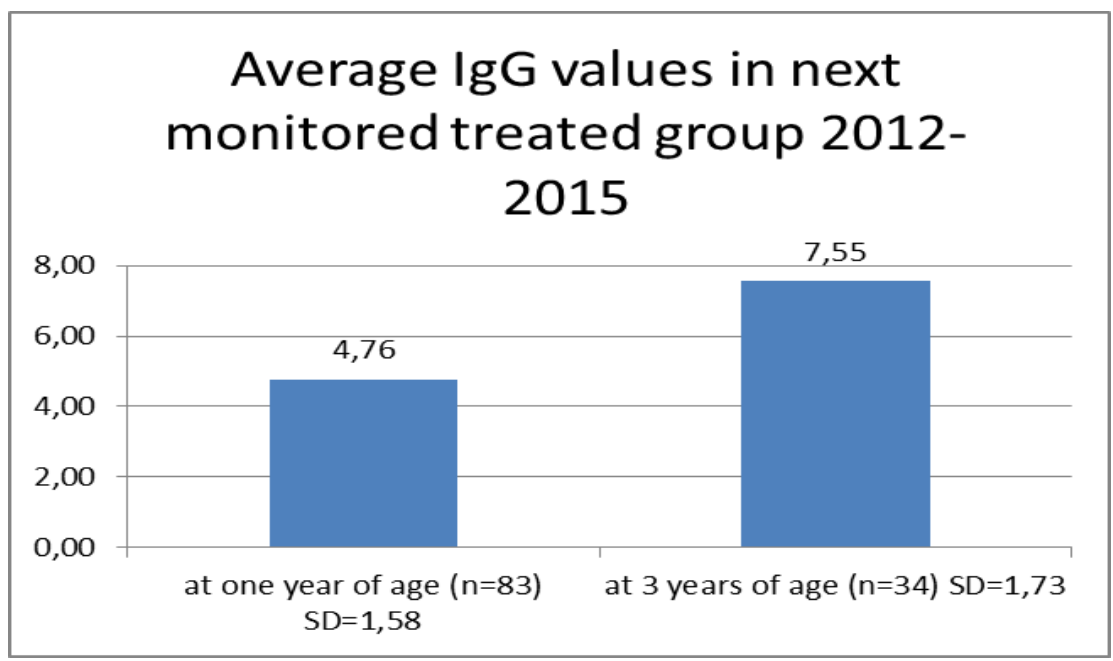

Fig. 10 Average IgE values in next monitored treated group 2012-2015. 


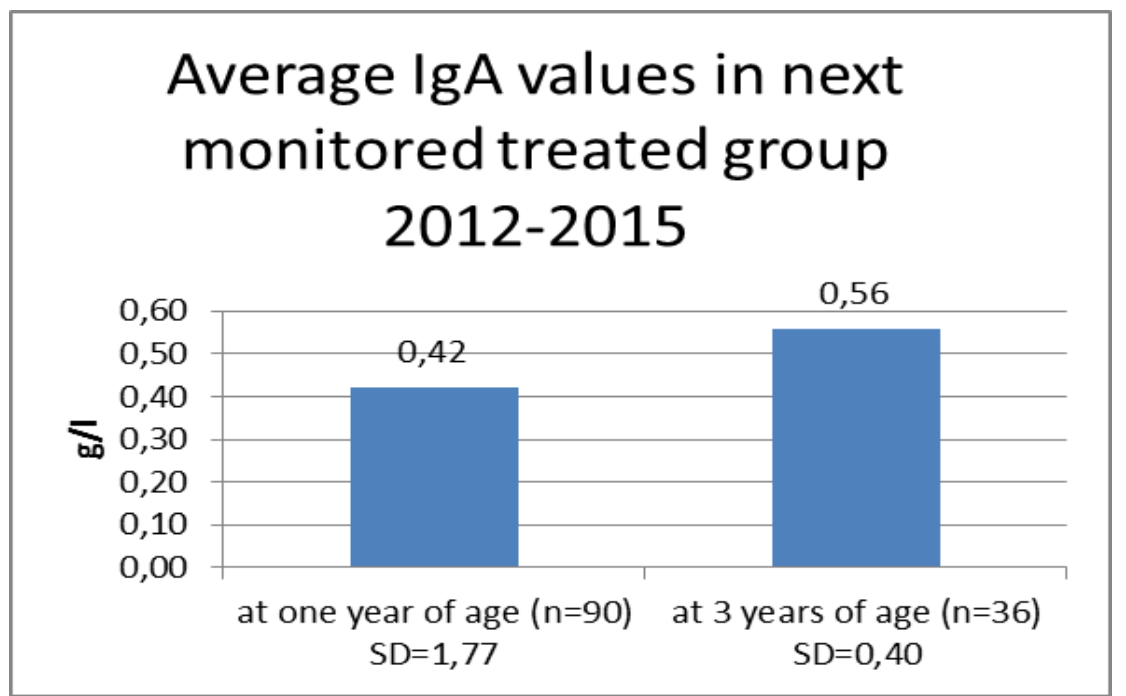

Fig. 11 Average IgA values in next monitored treated group 2012-2015.

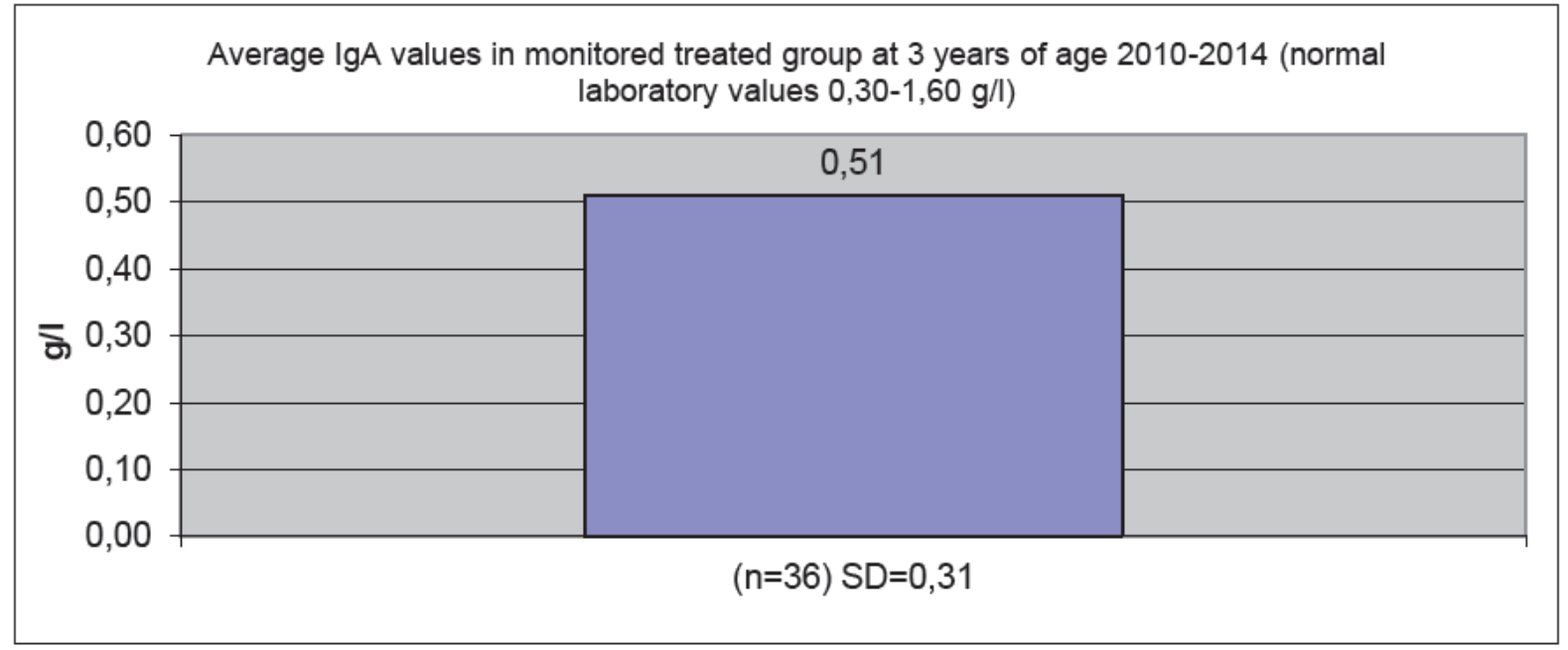

Fig. 12 Average IgA values in monitored treated group at 3 years of age 2010-2014 (normal laboratory values 0.30-1.60 g/l).

treated children up to the age of three years.

Fig. 15 is depiction of morbidity in treated children after three years of age with Colinfant.

\section{Statistics}

Immunoglobulin values changed over time, between the 1st-3rd years of life with a significance level of $10 / 00$. IgG treated children increased in median from 4.55 to 6.87. IgA treated children increased in median from 0.26 to 0.62 . IgE treated children increased in median only from 8.87 to 17.09 . The values remained completely within the standard.

$\mathrm{P}+++$ statistical significance was reached at the level of 1 promile, i.e. a significant protective effect, increased IgE and IgA. A significant decrease in IgE was in line with the decreased illness rates in these patients. The development in time at controls was not tested for a small number complete pairs of measurements.

Correlation of Variables in Controls

At 1 year of age in treated subjects, there were statistically significant correlations between IgG and IgA at a significant level of $10 / 00$. Correlation was positive and directly proportional. At 1 year of age, the umbilical IgE was correlated with all serum immunoglobulins, and most with IgG and IgA. P level 
114 Significance of Immunoglobulin E in Umbilical Blood in Relation to an Allergic Family History, Seasonality, Child Immunity and the Impact of Applied Non-pathogenic E. coli on Children's Microbiome

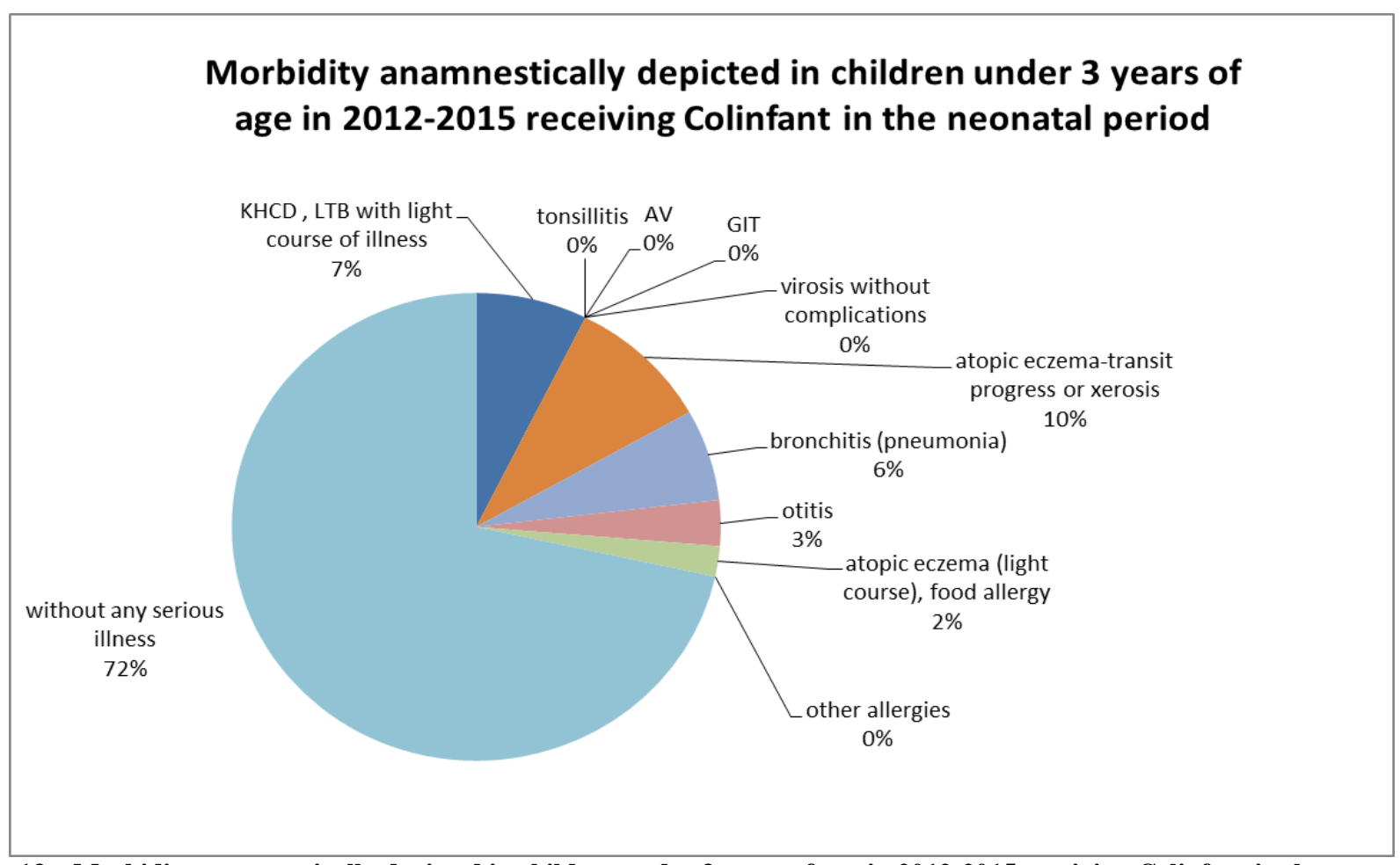

Fig. 13 Morbidity anamnestically depicted in children under 3 years of age in 2012-2015 receiving Colinfant in the neonatal period.

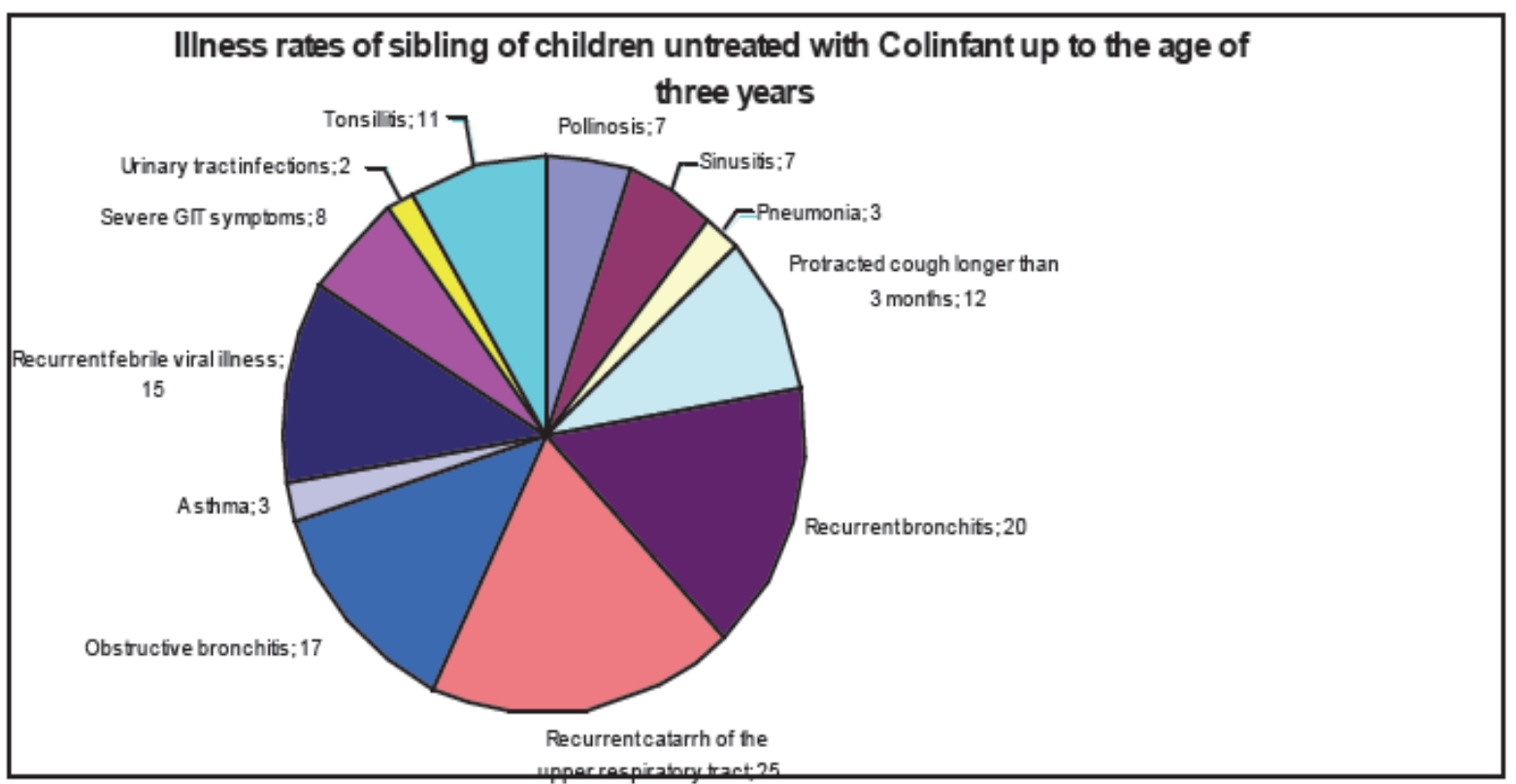

Fig. 14 Illness rates of sibling of children untreated with Colinfant up to the age of 3 years. 


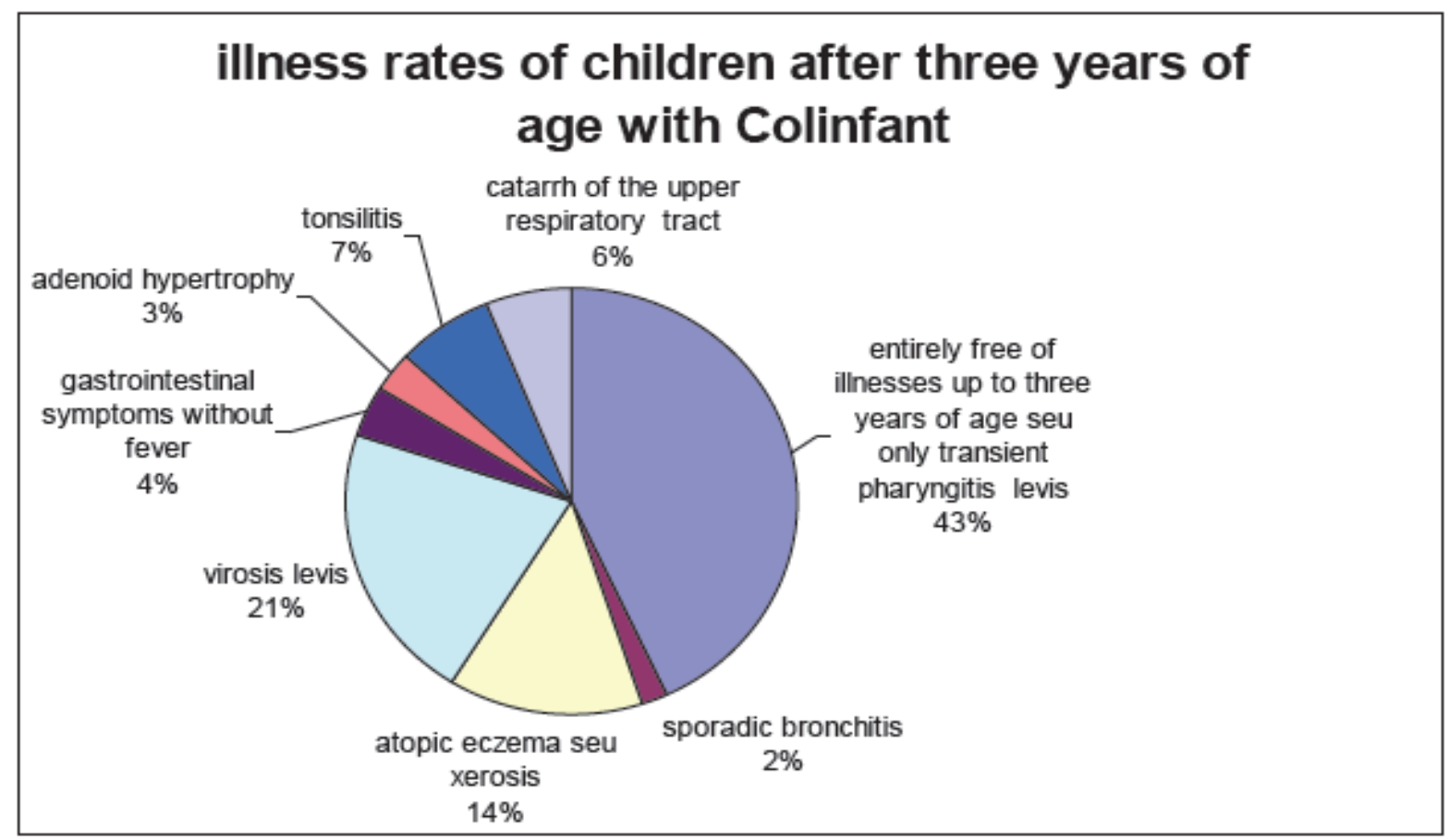

Fig. 15 Illness rates of children after three years of age with Colinfant.

of significance at 1 promile (+++) and $10 / 0$ reflects the positive clinical and laboratory status of the subjects.

At 3 years of age, there were statistically significant correlations between IgG and IgA at a significant level of $10 / 00$.

$\mathrm{P}$ level of significance $(+++)$, demonstrates a significant protective effect.

Statistical evaluation of treated groups 2012-2015 demonstrated significant difference between treated and control groups in IgA at year one and IgA at three years and IgE at three years at $\mathrm{P}$ level of significance $(+++)$.

At 1 year of age in 6 patients, there were statistically significant correlations between IgG and IgA at a significant level of 1 promile correlation which was positive and directly proportional. At 1 year of year of age umbilical IgE correlates with all serum immunoglobulins the most with IgG and IgA. P level of significance at 1 promile /+++/and $1 \% /++/$ reflects the positively clinical and laboratory status of the children.

At 3 years of age, there were statistically significant correlations between IgG and IgA at a significant level of 1 promile.

IgE in the treated children did not statistically significantly differ from the reference values for healthy children. About $95 \%$ of treated children by the age of three years were minimally ill. The use of antibiotics in these children was exceptionally rare with the vast majority of treated children having never been treated with antibiotics.

\section{Discussion}

From 1998 to 2015 we examined 4,312 samples of umbilical cord blood. As far as the authors know this is the longest study to measure IgE in umbilical cord blood. From the entire group of newborn children with elevated IgE, 335 were subsequently treated with Colinfant. All had both case-history and laboratory examinations performed just after the first and third years of life.

Our study demonstrates a clear correlation with changing seasons, with the highest levels seen during spring and summer births. There are conflicting findings in the literature in this regard, though our 
results were most clear during the entire duration of 17 years. IgA was also always evaluated in order to rule out the possibility of maternal blood mixing with that in the fetus.

In recent decades we have seen a significant rise in the allergic disease in early childhood.

Our study initially began with the aim of determining if the levels of IgE in the umbilical blood are predictive of allergic disease in children by the age of 18 months and by the age of 3 years of life. We discovered a strong predictive value of $\operatorname{IgE}$ as a prognostic indicator of future allergy. It is known that the immune system may be influenced prenatally in utero, at a time when allergens may pass through the placenta [1, 2]. For this reason our study was aimed at the perinatal and prenatal period and the factors that may influence a rise in allergies in early childhood. A critical period when external factor may affect the immune system is during the first month of life [3-8].

It has also been previously determined that a positive association exists between the placenta, placental microbiome and the metabolic health of children [9]. The microbiome is defined as the totality of microorganisms and their collective genetic material present in or on the human body and consists of 10-100 trillion symbiotic microbial cells, with bacterial genes exceeding those of the host genetic makeup by over a hundred times. The maternal microbiome plays a paramount role during pregnancy. The initial development and maturation of the neonatal microbiome is determined by maternal-offspring exchange of microbiota. The neonatal microbiome, and hence metabolic or immunological disease risk may be influenced by the mode of birth delivery, the use of antibiotics perinatally and the mode of feeding. Disturbing the transmission or between mother and child may lead to increased risk of celiac disease, asthma, diabetes and obesity. The consumption of probiotics during pregnancy may change the expression of Toll-like receptors, TLR genes in the placenta, and the expression of Toll-like receptor genes in the placenta and meconium. Newborn children born to mothers that used antibiotics during pregnancy, those born by caesarian section and those not breastfed may benefit from using pre/probiotics in order to positively influence their microbiome. This may then lead to a reduction of allergic and autoimmune disease, and infant colic. We believe that by influencing infants' microbiome it will be possible to influence epidemiological trends in immune and metabolic diseases.

A child's immune system is immature in the first months of life and progressively develops in order to achieve optimal protection. A newborn produces only a relatively small amount of immunoglobulins and thus cell specific immunity reaction to antigens is limited. In these children, there is primarily a misbalance between Th1 and Th2 lymphocytes in favor of Th2, and thus a higher chance of atopic sensitization. Furthermore, on the basis of a polygenic foundation there is a possibility of sensitization of the fetus from the twenty second week of pregnancy through increased production of IgE, IL4 and IL5. Newborns also have an immaturely developed mucosal barrier which presents another entry point for potential allergens [3, 8, 10, 11].

It has been suggested that it may be appropriate to determine IgE in the newborn of atopic parents, such that a measured high level may indicate a higher potential risk of allergy [4, 12, 13]. The genetic makeup of an individual significantly influences the initiation and progression of allergic reactions.

During the course the last century since, there has been a significant reduction of wide-scale infectious and parasitic diseases, and thus it has been proposed that the human immune system has switched into becoming more sensitive to common potential allergens.

An important role is played by chromosome 5, location CD14 which contains an array of genes for cytokines including IL4 [4]. 
A key mediator in allergic reactions is IgE [14]. We may also suggest that the allergic phenotype lies at the level of cells in umbilical blood. By investigating umbilical blood and the cytokines therein, we may predict an allergic predilection from the 22nd week of pregnancy. A significantly higher amount of IL5 and IL10 in the colostrum of allergic mothers and in the cord serum leads to a Th2 weighted immune system [6]. The decreased expression $\mathrm{f}$ TGF-B u children of allergic mothers may lead to a slowed maturation of gastric mucosa and thus lead to increased infiltration by potential allergens [8].

In the literature no correlation has been found between IgE of allergic mothers and their children up to the age of 6 months. The fetal immune system receives its first allergenic impulses during pregnancy, with a maximum in the last trimester when the placental microbiome plays a critical role [3, 7, 9].

There are low levels of specific IgE against food and airborne allergens in most newborn children.

In vitro studies have shown that CD4 $\mathrm{T}$ lymphocytes from cord blood of atopic children produce greater amounts of IL4 than the CD T lymphocytes of children born to non-atopic parents [6].

During the first year of life the immune system matures as $\mathrm{s}$ result of antigen exposition and thus begins to develop into a Th1 type profile. In atopic children however this reorganization does not appear, and the Th2 type profile continues with increased production of IL4 and IL5.

These play a critical role in the regulated formation of IgE. With the less than optimal IgA in newborn there is also a deficiency of regulatory antibodies. This in turn results in increased permeability of the intestinal mucosa to potential antigens and thus leading to increasing production of IgE. This process is enhanced by a deficit of $\mathrm{T}$ suppressive lymphocytes - a state that is typically found in allergic diseases $[15,16]$. IgE is carrier of reagin activity.

The serum IgE concentration is about $41 \%$ of the total amount in the body with the remainder being bound to mastocyte cell receptor and basophil granulocytes. The half-life of the bound IgE is approximately 2 weeks. The synthesis of IgE is regulated by $\mathrm{T} 4$ lymphocytes and the genotype of the individual. IgE takes part in the immunopathologic type 1 reaction which leads to clinical signs of atopy. This reaction occurs in those that have a genetic predisposition in response to the presence of some antigens and leads to the formation of the antibody isotype IgE. The synthesis of IgE has been found to occur from the 11th week and thus the concentration in cord blood is a reflection of its production. Lymphocytes carrying IgE have been found in cord blood.

Atopic mother's diet has not been found to influence the development of food allergies in their children irrespective of whether this diet was altered in the first trimester or in late pregnancy $[17,18]$.

The elucidation of IgE in cord blood of children does not only have a theoretical significance in determining future life dynamics, but most importantly plays a prognostic role for the risk of allergy, especially if the concentrations exceed two standard deviations above normal levels [7, 12, 16]. This is however somewhat controversial [19]. The risk of sensitization in the first 6 months is significant because of low enzyme levels in the immature mucosa of the gastrointestinal tract, and immature mucosal immune system with a decreased oral tolerance and relatively compromised absorption of macromolecules from the intestinal lumen [20].

Oral tolerance is the specific inhibition of the immune reaction process following a previous contact with of a specific antigen with regulatory cells located in the intestinal mucosa. This induction does not occur in the mucosa of the respiratory system where the same antigen infers a protective reaction.

In our study, from 1999-2008, it is apparent how substantial the impact of weather, or more specifically the pollen season had on cord IgE in children born to 
118 Significance of Immunoglobulin E in Umbilical Blood in Relation to an Allergic Family History, Seasonality, Child Immunity and the Impact of Applied Non-pathogenic E. coli on Children's Microbiome

families, with a significant history of allergy compared with controls. This may open a controversial question of the benefits of planned delivery during periods of low pollen formation.

A less than optimal contact with bacterial antigens is considered a factor that may lead to the development of allergy. Because children are born with an immature specific immune response, it is necessary to present a sufficient level of stimulation. Probiotic bacteria present such a possible source that may reduce the future manifestation of allergic and autoimmune diseases by enabling the evolution of healthy intestinal mucosal and a regulated immune system.

It is important to enable oral tolerance during the first six months of life through active stimulation of the immune system through the application of probiotics.

It is known that the specific immune response with Th2 weighting develops from the time of delivery. The rationale for treatment with Colinfant is the redirection of immune memory of the allergic type from Th2 phenotype before the immune response occurs to external stimuli.

In atopic children with clinical signs of allergic disease there is a Th2 weighted immune response in comparison with non-atopic children there is a Th1 weighted response.

Immunotherapy of allergic disease reduces the formation of interleukin 4 (IL-4) specific Th2 lymphocytes and increases the production of IFN-gamma specific Th1 lymphocytes.

The mucosal lymphatic system is the largest part of the immune system and comprises $80 \%$ of the immune competent cells in the human body. Combined with an optimal composition of a physiological bacterial microflora the induction of an immune reaction leads to the production of cytokines that enable active tolerance to harmless allergens.

The negative reoccurring application of Th2 lymphocytes leads to not only the stimulation of IgE, but also the increased secretion of IgA and via interleukin 4, leads to suppression of Th1 lymphocytes. IgE response relies on the interaction between $\mathrm{T}$ cells and antigen presenting cells. To date the liver has been recognized as the most metabolically active organ. However gastrointestinal flora is now known to infer an equally high metabolic activity and also have an effect of lowering luminal $\mathrm{pH}$, increased production of mucin and modulation. Therapy with probiotics presents a possibility of introducing specific microbes into the gastrointestinal tract. These must remain in viable form during production, storing and passage through the GIT tract.

Stimulation of the immune system also occurs via interaction with Toll-like receptors on dendritic cells. Probiotics are also able to support natural immunity through the production of antimicrobial peptides called defensins.

In addition to the previously mentioned information regarding Colinfant Newborn, a new peroral vaccine containing lyophilized non-pathogenic strains of $E$. coli which represent a group of bacteria normally associated with GIT microflora. It has ideal colonization potential due to the presence of fimbriae hemagglutination. We emphasize that this is a non-pathogenic strain which is highly selective and stimulates the induction of IgA immunoglobulins in the newborn [22].

Overall we included 4 groups: 2005-2007, 2008-2009, 2010-2014 and 2012-2015. The results were collated, graphically presented and the statistics calculated. Eighty percent of treated newborn children with high IgE and a positive family history demonstrated a significant decrease of IgE to normal levels at the age of one and three years [23]. Although in the remaining twenty percent a normalization of concentrations was not observed, these children did not demonstrate any symptoms or signs of allergy. This may be explained by the possibility of regulatory or inhibiting antibodies. IgA and IgG in the treated children were also significantly affected. The 
correlated statistical significance of IgE and IgA was found to be from 1 promile to 1 percent. The marked low rate of infectious morbidity may be due to the normalization of immunoglobulins of the specific and nonspecific immunity.

Ninety percent of children treated with Colinfant from 2005-2007, 2008-2009, 2009-2014, 2012-2015 had significantly reduced IgE in all groups, 10 percent of children had no clinical symptoms of allergy and yet still maintained significantly high IgE values in their serum. We expect that this is due to the presence of regulatory antibodies. Furthermore all of these treated groups had very low illness rates as presented in the graphs. We then further investigated the reasons for this reduced morbidity and discovered that treated children had greater IgG values when compared with controls and reference values. It is known that atopic children and those with higher morbidity rates have relatively low levels of IgA between the first and third year of life. However our treated children in all treated groups had normal reference levels.

We believe that the basis for defense capacity of children is at least in part due to the positive influence of probiotics on their microbiome. A critical time for this priming is in the first two years of life since it is known that the standard microflora found in adults begins colonization from two years of life. We expect that from the age of twenty years the inherent gastrointestinal flora has fully become stable and may not be significantly altered. Indeed there are suggestions in the literature that the application of probiotics in adulthood may have an autoimmune effect, and for this reason it is thought that prebiotics may be a superior alternative.

During the eighteen years of our study we have confirmed that cord IgE concentrations are predictive of allergic disease in children up to the age of three years. Clear differences in seasonality have been observed and indeed that future allergic disease in newborns may be influenced in the final 6 weeks of pregnancy. We believe that an allergenic environment may influence the fetus and its microbiome and hence it's potential for atopicity [23-25].

We must emphasize that IgE production in the human foetus begins in the liver, lung and spleen from the twenty first week of gestation [27]. Bosquet et al. [7] have found that IgE values in cord blood are a predictive risk factor for the future development of atopy.

The first versions of probiotics were mentioned by Mečnikov [28], who highlighted the importance of intestinal microflora and its important role in immune defense. It appears that colonization of the mucosal epithelium with a specific bacterial type has both nutritional and immunological importance. They may reduce mucosal pathogen and reduce the number of intraepithelial regulatory $\mathrm{T}$ lymphocytes on the epithelial surface and thus increase their antigen presentation [28]. The ability of probiotics to influence intestinal flora has been documented in many studies [13, 21, 26, 29-37].

To be included amongst probiotics they must fulfill several criteria. So far gene typization has been performed on only 3 kinds of probiotics: E. coli type Nissle, E. coli 83 Colinfant and Lactobacillus casei species, Rhamnossus-lactobaciluus GG and Saccharomyces boullardi. The latter, however, is not originated from human and may not belong amongst true probiotics. The form in which probiotics are applied into the gastrointestinal system should contain adequate amounts to confer a beneficial health effect on the host.

Today it is known that allergy manifests itself during the first three years with gastrointestinal symptoms, atopic eczemas and respiratory problems.

The beneficial role of probiotics in atopic eczema is controversial [38, 39]. The failure of probiotics in this regard has been also published [40]. Rarely, negative effects of probiotics have occurred in immunocompromised and chronically ill children [41]. On the other hand, other authors [30] have affirmed that probiotics may reduce the incidence of IgE 
associated eczemas in infants. The anti-infective effect of probioitcs has repeatedly been attributed to the stimulation of nonspecific immunity stimulation. Fukushima et al. [22] suggested that the application of bifidobacteria caused significantly increased fecal IgA level and anti-poliovirus IgA. This increase may indicate a stronger resilience against GIT infections. Some bifidobacteria stimulate microbiom in vitro. During application the number of bacteria in the stool increased and upon withdrawal of the probiotics the number in the stool reduced. The possible effect of probiotics may be due to alterations in intestinal permeability, stimulation of immune response to pathogens, the increased production of secretory IgA , IgG, IgM, and the anti-inflammatory cytokines interleukin 10 and TGF beta [42].

Ideal and optimal gastroflora content leads to the induction of an immune reaction that leads to the production of cytokines that affect an active tolerance to harmless antigens. Other authors [20] have demonstrated the unquestionable positive effect of probiotics in the prevention of GIT problems in infants and the rapid positive clinical effects in rotaviral infections.

Authors that concern themselves with neonatal issues have declared that giving mothers probiotics before and six months after birth did not have any effect on preventing allergic disease. All of these studies used probiotics containing Lactobacillus rhamnosus, reuteri or B. lactis. Some also gave prebiotic oligosaccharides during the first six months of life and attributed the protective effects to the fact that these were applied from the first days of life.

Other studies claimed prevention of enterocolitis in very low birth weight children by the use of probiotics [43, 44].

On the other hand some authors [45] have hypothesized a protective effect of early introduction of cow's milk due to protection against IgE.

When breast feeding is not possible, international associations concerned with nutrition recommend hydrolyzed or partially hydrolyzed infant formulae with low allergenicity up to the age of 4 months. The previous suggestions of excluding allergens in the nutrition of children up to the age of six months have been sidelined. In our cohort of non-breastfed patients we recommended the exclusive use of hypoallergenic HA BEBA formula.

Authors [46] have agreed the most intensive colonization happens during the first month of life and progressively decreases around the first year of life and remains at a constant to adulthood. Others have suggested that delayed colonization due to birth by caesarian section may be associated with the development of atopic eczemas which appear between the first and second year of life. On the other hand other studies have demonstrated that the application of probiotics benefitted primarily children with IgE based allergy [7].

Phagocytic cells whose cytokines regulate inflammatory reactions are active part of the natural immune mechanism. $M$ cells actively transport antigens from the intestinal lumen. Dendritic cells then present the antigens to $\mathrm{T}$ lymphocytes. The production of IL-10 and TGF leads to the activation of $\mathrm{T}$ lymphocytes and induces oral tolerance. Pathogenic microorganisms activate $\mathrm{T}$ lymphocytes and their cellular response. Secretory IgA antibodies, part of the humoral immune reaction, prevent the penetration of antigens from the intestinal lumen.

The possibility of positively affecting gastrointestinal flora with probiotics has been discussed in many works [33, 47-51]. The rationale for treatment with probiotics lies in redetermining the immune response from Th2 to the Th1 phenotype before the immune response reacts to the antigens in the immediate environment. The immune system in early neonatal life lacks prompt contact with microbes and allergens that are important for the stimulation and regulation of a healthy and functional immune system [52].

This may then lead to an immature and Th2 skewed 
pathway. In addition, there seems to be a mechanism of induction of immunological tolerance up to 2 years of age.

The concentrations of newborn cord IgE treated with Colinfant as well as their values at one and three years were presented in the results, as were those of IgG and IgA. These concentrations were significant.

We were surprised by the normalized IgG and IgA levels, as demonstrated in children from 2010-2014 where there were significant differences between treated and controls.

The effect of colonization of the gastrointestinal tract is evident by the induction of immune tolerance and this in turn leads to the normalization of IgG and IgA and reduced IgE. These factors in turn lead to significant reduction of morbidity. Because newborns have an immature immune system, we suggest that they may have reduced interferon gamma as a result of reduced T1 helper cells function. Repeated contact with microbes may then benefit maturity of the microbiome.

The reduced production of interferon gamma $\mathrm{T}$ lymphocytes and the reduced production of IL-4 and 5 may result in delayed eradication of viruses, increased epithelial damage and amplification of allergic inflammation. Instead of interferon gamma, $\mathrm{T}$ lymphocytes produce IL-4 and 5. IL-4 then stimulates B lymphocytes to produce IgE. A deficit of immunoglobulins a concomitant deficit of regulatory antibodies, leads to a further increase in IgE [53].

During viral infections there is also an increased IL-8 production that leads to bronchial reactivity. It is known that children with food allergies may also have increased allergy to inhaled allergens.

In our previously published study we demonstrated that neonates born to parents with allergies had increased levels of AGEs (advanced glycation end products) in their umbilical cord blood [11]. AGEs activate long lasting inflammation, followed by free radical production via NF kappaB formation. Furthermore they repress some endogenous autoregulatory functions leading to many diseases including allergy. CD4 T lymphocytes in parents of atopic children produce larger quantities of IL4 than CD4 lymphocytes of non-atopic parents. Th2 lymphocytes release IL-4 and IL-5. Induction of IgE response is dependent upon the interaction between $\mathrm{T}$ cells by antigen presenting cells, and this leads to preferential stimulation of IL-4 and INF Gamma. Effect of probiotics plays the important role on the decline of luminal $\mathrm{HH}$ and modulation of the immune system through interaction with $\mathrm{S}$ tool-like receptors on dendritic cells presented in the epithelium. Probiotics are able to support additionally the natural immune system through stimulation of antimicrobial active peptide substances like defensins, which improve the quality of mucosal barrier.

The use of umbilical blood, as a reflection of the placental microbiome, has been demonstrated to be a highly useful detection for predicting future allergy development in children. Our work suggests that a maternal phenotype of allergy is not entirely predictive of a similar phenotype in her child. The role of the placental microbiome may be equally important in determining the concentrations of IgE in umbilical blood.

Our work has demonstrated the benefits of probiotic therapy to influence allergic disease and morbidity in early life. With increasing antibiotic resistance this presents a new possibility in biotechnological strategies.

We believe that our results may indeed influence the future planning of pregnancy and delivery to avoid a higher risk of atopy in children.

Our work expands on current knowledge regarding effective and early stimulation of a newborn's maturing immune system.

Our study over eighteen years was carried out entirely at one study center and all investigations were done by the same group of authors and laboratory. All participants were intensively followed through close communication with parents and the children's 
general practitioner to objectively morbidity over three years.

We recognize that an important pitfall of our research was that the study was modified and adapted over consecutive years based upon new findings that stimulated further investigative procedures.

\section{Conclusions}

(1) There is a clear correlation of seasonality with regards to IgE with higher levels found in children born during high pollen seasons. Controversially this may influence family planning in high risk families.

(2) Treatment of 335 at risk children with Colinfant proved a valid and useful preventive strategy in significantly reducing future morbidity and allergic symptoms.

(3) Treatment with Colinfant significantly affected levels of IgE, IgA and IgG to the level of 1 promile.

(4) As practically no negative adverse effects of treatment were observed in this large study, we recommend the wide-spread use of similar probiotic preparations in all risk children during their neonatal stage of life.

(5) Breastfeeding does not appear to be protective against future allergy.

(6) Mode of delivery does not appear to directly affect predisposition to allergy.

(7) Placental microbiome appears to play an important role in the future incidence of allergy.

(8) Our study supports the notion of early primary stimulation of the neonatal microbiome in preventing future allergy and morbidity.

\section{Acknowledgements}

The authors thank the members of obstetrics-gynecology department, led by head physicians Z. Kestř́nek, M. D., and Z. Knaizl, M. D. for their cooperation.

The authors thank co. Dyntec, Terezín for continual providing Colinfant to the Pharmacies in the Czech Republic.
The authors thank doc. Petr Panzner, M. D. et Ph.D., Head of Clinical Immunology and Allergology Department of the University Hospital in Plzeň, for his valuable guidance.

Individual results of the work were repeatedly presented on the paediatric congresses in the Czech Republic and Slovakia with international participation in 2000, 2001, 2002, 2006 and 2008 and on Europaediatrics Congress in 2008 in Istanbul.

Contributions of this paper were presented on 4th Biotechnology World Congress in Sharjah, United Arab Emirates, February 15-18, 2016 and on Drug Discovery and Therapy World Congress 2016 in Boston, USA, August 22-25, 2016.

\section{Conflict of Interest}

The authors declare that they have no competing interests.

\section{Compliance with Ethical Standards}

This article does not contain any studies with human participants or animals performed by any of the authors.

\section{References}

[1] Salvatore, S., Keymolen, K., Hauser, B., and Vandenplas, Y. 2005. "Intervention during Pregnancy and Allergic Disease in the Offspring." Pediatr. Allergy Immunol. 16: 558-66.

[2] Wassenaar, T. M., and Panigrahi, P. 2014. "Is a Foetus Developing in a Sterile Environment?” Letters in Applied Microbiology 59 (6): 572-9.

[3] Glaser, J., and Johnstone, D. E. 1953. "Prophylaxis of Allergic Disease in the Newborn." J. Am. Med. Assoc. 153: 620-2.

[4] Romagnini, E., et al. 1991. "Increased Numbers of Th2-like CD4+ $\mathrm{T}$ Cells in Target Organs and in the Allergen-Specific Repertoire of Allergic Patients. Possible Role of IL-4 Produced by Non-T Cells.” Int. Arch. Allergy Appl. Immunol. 94 (1-4): 133-6.

[5] Kaufman, H. S. 1971. "Allergy in the Newborn: Skin Tests Reactions Confirmed by the Prausnitz-Künster Test at Birth.” Clin. Allergy 1 (4): 363-7.

[6] Hrdý, J., et al. 2007. "Exprese cytokinů v buňkách pupečníkové krve a cytokiny $\mathrm{v}$ prenatálním a časném postnatálním období dětí zdravých a alergických matek. 


\section{Seasonality, Child Immunity and the Impact of Applied Non-pathogenic E. coli on Children's Microbiome}

(Cytokine Expression Values in Cord Blood Cells and Cytokines in the Prenatal and Early Postnatal Period of Kids with Healthy and Allergic Mothers)." Vox Pediatriae 10 (8): 32.

[7] Bousquet, J., Ménardo, J. L., Viala, J. L., and Michel, F. B. 1983. "Predictive Value of Cord Serum IgE Determination in the Development of 'Early On-set' Atopy.” Ann. Alergy 51: 291-5.

[8] Isolauri, E., Kalliomäki, M., Laitinen, K., and Salminen, S. 2008. "Modulation of the Maturing Gut Barrier and Microbiota: A Novel Target in Allergic Disease.” Cur. Pharm. Des. 14 (14): 1368-75.

[9] Mueller, N. T., Bakacs, E., Combellick, J., Grigoryan, Z., and Dominguez-Bello, M. G. 2015. "The Infant Microbiome Development: Mom Matters.” Trends. Mol. Med. 21 (2): 109-17.

[10] Miller, D. L., Hirvonen, T., and Gitlin, D. 1973. "Synthesis of IgE by the Human Conceptus." J. Allergy Clin. Immunol. 52 (3): 182-8.

[11] Liska, J., Holeček, V., Siala, K., Sobotová, Š., Trefil, L., Racek, J., Sýkora, J., and Šefrna, F. 2016. “Umbilical IgE and Advanced Glycation Products in Association with Allergies in Childhood.” Immun., Endoc. \& Metab. Agents Med. Chem. 16: 142-5.

[12] Kjellman, N. I., and Johannson, S. G. 1976. "IgE and Atopic Allergy in Newborns and Infants with a Family History of Atopic Disease.” Acta Paediatr. Scand. 65 (5): 601-7.

[13] Petrů, P., and Špičák, V. 2004. "Vývoj alergie v průběhu života (Development of Allergy during Their Lifetime).” Alergologie. Galén, 149-51.

[14] Zavázal, V. 1983. "Atopie a imunita (Atopy and Immunity).” UK Praha 21-58.

[15] Edenharter, G., Bergmann, R. L., Bergmann, K. E., Wahn, V., Forster, J., Zepp, F., and Wahn, U. 1998. "Cord Blood-IgE as Risk Factor and Predictor for Atopic Diseases.” Clin. Exp. Allergy 28 (6): 671-8.

[16] Lilja, G., Johansson, S. G., Kusoffsky, E., and Oman, H. 1990. "IgE Levels in Cord Blood and at 4-5 Days of Age: Relation to Clinical Symtpoms of Atopic Disease up to 18 Months of Age.” Allergy 45 (6): 436-44.

[17] Bazaral, M., Orgel, H. A., and Hamburger, R. N. 1971. "IgE Levels in Normal Infants and Mothers and an Inheritance Hypothesis.” J. Immunol. 107 (3): 794-801.

[18] Rutten, N., Van der Gugten, A., Uiterwaal, C., Vlieger, A., Rijkers, G., and Van der Ent, K. 2016. "Maternal Use of Probiotics during Pregnancy and Effects on Their Offspring's Health in an Unselected Population.” Eur. J. Pediatr. 175 (2): 229-35.

[19] Shah, P. S., et al. 2011. "The Relationship between Cord Blood Immunoglobulin E Levels and Allergy-Related Outcomes in Young Adults.” Ann. Allergy Asthma.
Immunol. 106 (3): 245-51.

[20] Saavedra, J. M., et al. 2007. "Use of Probiotics in Pediatrics: Rationale, Mechanisms of Action and Practical Aspects.” Nutrition in Clinical Practice 22 (3): 351-65.

[21] Liška, J., Siala, K., Holeček, V., Sobotová, Š., Kepková, M., and Šefrna, F. 2014. "Effect of Early Treatment of Newborns by Peroral Colonization Using Non-pathogenic E. coli on the Development of Their Immuno-allergic System.” Clinical Anti-Inflammatory \& Anti-Allergy Drugs1: 111-21.

[22] Fukushima, Y., Kawata, I., Hara, H., Terada, A., and Mitsuoka, T. 1998. "Effect of a Probiotic Formula on Intestinal Immunoglobulin a Production in Healthy Children.” International Journal of Food Microbiology 42: 39-44.

[23] Strimas, J., et al. 1988. "Significance of IgE Level in Amniotic Fluid and Cord Blood for the Prediction of Allergy.” Ann. Allergy 61 (2): 133-6.

[24] Matsumura, T., et al. 1970. "Congenital Sensitization to Food in Humans.” Alergia 17 (4): 163-71.

[25] Blumenthal, M. N., et al. 1986. "Preventive Allergy: Genetics of IgE-Mediated Diseases.” J. Allergy Clin. Immunol. 78: 962-8.

[26] Businco, L., et al. 1983. "Predictive Value of Cord Blood IgE Levels in 'At-risk' Newborn Babies and Influence of Type of Feeding.” Clin. Allergy 13 (6): 503-8.

[27] Novák, J., and Novotná, B. 2012. “Allergy and Asthma.” GRADA.

[28] Mečnikov, E. 1908. The Prolongation of Life; Optimistic Studies. London G.P.Putnam`s Sons .

[29] Neaville, V. A., et al. 2003. "Developmental Cytokine Response Profiles and the Clinical and Immunological Expression of Atopy during the First Year of Life." $J$. Allergy Clin. Immunol. 112: 740-6.

[30] Abrahamsson, T. R., et al. 2007. "Probiotics in Prevention of IgE-Associated Eczema: A Double-Blind, Randomized, Placebo-Controlled Trial.” J. Alerg. Clin. Immunol. 119 (5): 1174-80.

[31] Pepys, J. 1973. "Immunopathology of Allergic Lung Disease.” Clin. Allergy 3: 1.

[32] Hamburger, R. N., Lenois, M., Groshong, T. E., Miller, R., and Orgel, H. A. 1974. "Development of IgE and Allergy during the First Year of Life: Preliminary Data.” J. Allergy Clin. Immunol. 539: 4A.

[33] Björkstén, B. 2004. "Effect of Intestinal Microflora and the Environment on the Development of Asthma of Allergy." Springer Semin Immunopathol 25 (3-4): 257-70.

[34] Kukkonen, K., et al. 2007. "Probiotics and Prebiotics Significantly Prevent Eczema and Atopic Eczema in Infants.” J. Allergy Clin. Immunol. 119 (1): 192-8. 
[35] Valsecchi, A., et al. 2008. "Probiotics demonstrate Immunomodulatory Effects in Atopic Pediatric Patients by Increasing the Th1 Immune Response Which Counterbalances the Dominant Th2 Immune Response.” Pediatr. Med. Chir. 30 (4): 197-203.

[36] Viljanen, M., et al. 2005. "Probiotics in the Treatment of Atopic Eczema/Dermatitis Syndrome in Infants: A Double-Blind Placebo-Controlled Trial.” Allergy. 60 (4): 494-500.

[37] Vliagoftis, H. 2008. "Probiotics for the Treatment of Allergic Rhinitis and Asthma: Systematic Review of Randomized Controlled Trials.” Ann. Alergy. Asthma. Immunol. 101 (6): 570-9.

[38] Kalliomäki, M., Salminen, S., Arvilommi, H., et al. 2001. "Probiotics in Primary Prevention of Atopic Disease: A Randomised Placebo-Controlled Trial." Lancet 357: 1076-9.

[39] Kalliomäki, M., Salminen, S., Poussa, T., et al. 2003. "Probiotics and Prevention of Atopic Disease: 4-Year Follow-up of a Randomised Placebo-Controlled Trial.” Lancet 361: 1869-71.

[40] Brouwer, M., et al. 2006. "No Effects of Probiotics on Atopic Dermatitis in Infancy: A Randomized Placebo-Controlled Trial.” Clin. Exp. Allergy. 36 (7): 899-906.

[41] Thomas, D. W., and Greer, F. R. 2010. "Probiotics and Prebiotics in Pediatrics.” Pediatrics 126: 1217-31.

[42] Vouloumanou, E. K., et al. 2009. "Probiotics for the Prevention of Respiratory Tract Infections: A Systematic Review.” Int. J. Antim. Agents 34 (3): 1-10, 197.

[43] Sochorová, V. 2003. "Podávání a účinky aplikace Colinfantu u nedonošených dětí (Administration and Application Effects of Colinfant in Preterm Infants).” Vox. Ped. 9, 7, 3, 26-7.

[44] Deshpande, G., et al. 2010. "Updated Meta-Analysis of Probiotics for Preventing Necrotizing Enterocolitis in Preterm Neonates.” Pediatrics 125 (5): 921-30.

[45] Katz,Y., et al. 2010. "Early Exposure to Cow's Milk Protein Is Protective against IgE-Mediated Cow’s Milk
Protein Allergy.” J. Allergy. Clin. Immunol. 126 (1): 77-82.

[46] Thon, V. 2011. "Intestinální mikroflóra v raném dětství úloha při rozvoji infekčních a alergických chorob (Intestinal Microflora in Early Infancy and its Role in the Course of Infectious and Allergic Diseases).” Pediatrie Pro. Praxi. 12 (4): 252-6.

[47] Braegger, C., Chmielewska, A., et al. 2011. "Supplementation of Infant Formula with Probiotics and/or Prebiotics: A Systematic Review and Comment by the ESPGHAN Comittee on Nutrition.” J. Pediatr. Gastroenterol. Nutr. 52 (2): 238-50.

[48] Henker, J., et al. 2007. “The Probiotic Escherichia coli Strain Nissle 1917 (EcN) Stops Acute Diarrhoea in Infants and Todlers.” Eur. J. Pediatr. 166 (4): 311-8.

[49] Kuitunen, M., et al. 2009. "Probiotics Prevent IgE-Associated Allergy until Age 5 Years in Cesarean-Delivered Children but Not in the Total Cohort.” J. Allergy Clin. Immunol. 123 (2): 335-41.

[50] Lilly, D. M., and Stillwell, R. H. 1965. "Probiotics: Growth-Promoting Factors Produced by Microorganisms.” Science 147: 747-8.

[51] Lodinová-Žádníková, R., and Cukrowská, B. 1999. “Vliv perorálního osídlení nepatogenním kmenem E.coli po narození na složení střevní flóry, imunitní odpověd' a výskyt nozokomiálních infekcí u donošených a nedonošených dětí. Sledování jeho dlouhodobého působení. (Effect of Peroral Settlement Nonpathogenic E. coli after Birth on the Composition of the Intestinal Flora, Immune Response and the Incidence of Nosocomial Infections of Infants Carried to Term and Preterm Infants).” Československá Pediat. 54 (6): 268-73.

[52] Penna, F. J., Péret, L. A., Vieira, L. Q., and Nicoli, J. R. 2008. "Probiotics and Mucosal Barrier in Children." Curr. Opin. Clin. Nutr. Metab. Care. 11 (5): 640-4.

[53] Ratner, B., and Greenburgh, J. E. 1932. "Congenital Protein Hypersensitiveness: Protein Hypersensitiveness Transmitted from Allergic Mother to Child.” J. Allergy 3: 149-60. 